\title{
Genital herpes: an increasing problem?
}

\author{
D J HINDLEY AND $M$ W ADLER \\ From the Academic Department of Genitourınary Medicine, Middlesex Hospital Medical School, \\ London WIN $8 A A$
}

SUMMARY Over the past 10 years there has been a pronounced increase in the number of cases of genital herpes seen in sexually transmitted disease (STD) clinics in the United Kingdom. The reporting system, however, does not differentiate between primary and recurrent infections, and consequently any increase in the number of patients reattending clinics with recurrent genital herpes would falsely inflate the statistics.

A study of cases of herpes seen in the department of genitourinary medicine of this hospital in the two years 1972 and 1982 is presented. It showed that the proportion of patients attending with recurrent herpes had increased from $18 \%$ in 1972 to $31 \%$ in 1982 . As a result of this, the $68 \%$ increase between 1972 and 1982 in the total number of cases of herpes seen in the clinic overestimates the real increase in the size of the problem, which is closer to $40 \%$, based upon cases of primary herpes only.

Modifications to the national recording system are necessary to overcome the problems highlighted by this study. These modifications could include classifying each case of genital herpes as primary, recurrent, or recurrent but not previously recorded, which would provide a more accurate picture of the size of the problem of genital herpes in the population.

\section{Introduction}

Between 1972 and 1982 the number of cases of genital herpes seen in sexually transmitted disease (STD) clinics in the United Kingdom increased by $230 \% .^{1}$ Interpreting the annual statistics for genital herpes, however, is particularly difficult as the disease is often recurrent. The statistics do not differentiate between primary and recurrent infection, which makes it difficult to know how much of the increase is due to an "epidemic" of patients with a first attack as opposed to those returning with recurrences.

The introduction of acyclovir ${ }^{2-4}$ and the increasing publicity in the media ${ }^{5-8}$ may have encouraged more patients with recurrent episodes to return expecting a cure by this agent or seeking reassurance that not all they read is true. ${ }^{9}$ More recurrent cases have therefore possibly been included in the published statistics in recent years than in the past. We examined this question.

\section{Patients and methods}

We studied a retrospective randomly selected 1 in 2 sample of men and women with genital herpes seen in

Address for reprints: Professor M W Adler, Academic Department of Genitourinary Medicine, Middlesex Hospital Medical School, London WIN 8AA

Áccepted for publication 8 June 1984 the department of genitourinary medicine at this hospital during the two years 1972 and 1982 . These two years were chosen because they were the first and the most recent for which complete data were available. From the clinic notes we recorded each patient's sex, sexual orientation, and age at the time the diagnosis was made, together with the source of referral and whether the patient was "old"-that is, had made a previous visit to the clinic for any reason-or "new". Each patient was classified as having either primary, if there was no history, or recurrent genital herpes. In each case of recurrent herpes the evidence for a previous attack was also recorded. Finally, for each patient the result of culture during the current attack was recorded.

The data were recorded on precoded forms and analysed using the statistical package for social sciences (SPSS). Tests of significance were performed using the $\chi^{2}$ method with Yates's correction when necessary.

\section{Results}

Of 385 patients with herpes seen in 1972, 193 were studied with a corresponding figure of 324 out of 648 patients in 1982. The proportion of men and women was similar for the two years $(63 \%$ men and $37 \%$ women in 1972, $61 \%$ men and $39 \%$ women in 1982) but a larger proportion of men were homosexual in $1982(33 \%)$ than in $1972(17 \%)(p<0.01)$. The 
TABLE I No (\%) of patients with primary and recurrent attacks of herpes during 1972 and 1982 by sex and sexual orientation

\begin{tabular}{|c|c|c|c|c|c|c|c|c|}
\hline \multirow{2}{*}{$\begin{array}{l}\text { Type of } \\
\text { attack }\end{array}$} & \multicolumn{2}{|c|}{ Heterosexual men } & \multicolumn{2}{|c|}{ Homosexual men } & \multicolumn{2}{|l|}{ Women } & \multicolumn{2}{|l|}{ Total } \\
\hline & 1972 & 1982 & 1972 & 1982 & 1972 & 1982 & 1972 & 1982 \\
\hline $\begin{array}{l}\text { Primary } \\
\text { Recurrent }\end{array}$ & $\begin{array}{ll}75 & (75 \cdot 0) \\
25 & (25 \cdot 0)\end{array}$ & $\begin{array}{ll}83 & (61 \cdot 9) \\
51 & (38 \cdot 1)\end{array}$ & $\begin{array}{rr}19 & (86 \cdot 4) \\
3 & (13 \cdot 6)\end{array}$ & $\begin{array}{ll}51 & (78 \cdot 5) \\
14 & (21 \cdot 5)\end{array}$ & $\begin{array}{rr}65 & (91 \cdot 5) \\
6 & (8 \cdot 5)\end{array}$ & $\begin{array}{ll}89 & (71 \cdot 2) \\
36 & (28 \cdot 8)\end{array}$ & $\begin{array}{r}159(82 \cdot 4) \\
34 \quad(17 \cdot 6)\end{array}$ & $\begin{array}{ll}223 & (68 \cdot 8) \\
101 & (31 \cdot 2)\end{array}$ \\
\hline Total & $100(100 \cdot 0)$ & $134(100 \cdot 0)$ & $22(100 \cdot 0)$ & $65(100 \cdot 0)$ & $71(100 \cdot 0)$ & $125(100 \cdot 0)$ & $193(100 \cdot 0)$ & $324(100 \cdot 0)$ \\
\hline
\end{tabular}

average (SD) age of patients with herpes in 1982 was $28 \cdot 1(7 \cdot 4)$ years compared with $26.9(6 \cdot 9)$ years in 1972. In $198229 \%$ of patients were referred from a specific source (such as a family planning clinic, general practitioner, or another clinic) rather than attending on their own accord, compared with only $14 \%$ of patients in 1972 . In both years just over half the patients seen with herpes were new attenders at the clinic.

A recurrent disease episode was evident in $18 \%$ of patients in 1972 compared with $31 \%$ in 1982 $(p<0.01)$ Table I shows that when heterosexual men, homosexual men, and women were considered separately the differences between years were similar, but were significant only in heterosexual men $(p<0.05)$ and women $(p<0.01)$.

TABLE II Patients with herpes seen in 1972 and 1982: percentage change between the two years

\begin{tabular}{llll}
\hline Type of attack & 1972 & 1982 & Increase (\%) \\
\hline Primary and recurrent & 193 & 324 & $131(67 \cdot 9)$ \\
Primary alone & 159 & 223 & $64(40 \cdot 3)$ \\
\hline
\end{tabular}

Table II shows that between 1972 and 1982 the total number or patients with herpes seen in the department of genitourinary medicine at this hospital increased by $68 \%$. For cases of primary herpes alone this increase was only $40 \%$. This difference in the percentage increase was simply a result of the larger proportion of patients with recurrent herpes seen in 1982.
Table III shows that cultures were performed more often in 1982 than 1972. Among patients for whom a culture test was performed, a larger proportion gave positive results in $1982(89 \%)$ than in $1972(71 \%)$. When primary and recurrent cases were considered separately significantly more cultures were performed in $1982(98 \%$ and $86 \%)$ than in $1972(78 \%$ and $71 \%)(p<0.001$ and $0.05<p<0.1$, respectively). Among patients with primary herpes for whom a culture test was performed, the proportion with positive results was significantly greater in 1982 $(94 \%)$ than in $1972(73 \%)(p<0.001)$. This was not so among patients with recurrent herpes for whom the proportion giving positive results was $76 \%$ in 1982 and $63 \%$ in 1972.

In $1982,28 \%$ of patients with recurrent herpes had had a previous attack confirmed by culture compared with only $9 \%$ in 1972 . Of patients with recurrent herpes for whom the only evidence of a previous attack was the patient's word, the proportion was similar in the two years $(30 \%$ in 1972 and $40 \%$ in 1982).

\section{Discussion}

The findings described in this paper indicate: firstly, that a proportion of cases of genital herpes reported by this hospital to the Department of Health and Social Security relate to patients with recurrent, as opposed to new or primary, disease episodes and, secondly, that between the years 1972 and 1982 this proportion increased significantly. This led to exaggerated figures both for the number of new cases seen yearly and for the increase in the size of the

TABLE III No (\%) of patients with primary and recurrent attacks of herpes in 1972 and 1982 for whom cultures were performed and No $(\%)$ of those giving positive results

\begin{tabular}{|c|c|c|c|c|c|c|}
\hline & \multicolumn{2}{|l|}{ Primary } & \multicolumn{2}{|l|}{ Recurrent } & \multicolumn{2}{|l|}{ Total } \\
\hline & $\begin{array}{l}1972 \\
(n=159)\end{array}$ & $\begin{array}{l}1982 \\
(n=223)\end{array}$ & $\begin{array}{l}1972 \\
(n=34)\end{array}$ & $\begin{array}{l}1982 \\
(n=101)\end{array}$ & $\begin{array}{l}1972 \\
(n=193)\end{array}$ & $\begin{array}{l}1982 \\
(n=324)\end{array}$ \\
\hline $\begin{array}{l}\text { Culture performed } \\
\text { Culture positive }\end{array}$ & $\begin{array}{r}124(78 \cdot 0) \\
90(72 \cdot 6)\end{array}$ & $\begin{array}{l}219(98 \cdot 2) \\
205(93 \cdot 6)\end{array}$ & $\begin{array}{l}24(70 \cdot 6) \\
15(62 \cdot 5)\end{array}$ & $\begin{array}{l}87(86 \cdot 1) \\
66(75 \cdot 9)\end{array}$ & $\begin{array}{l}148(76 \cdot 7) \\
105(70 \cdot 9)\end{array}$ & $\begin{array}{l}314(96 \cdot 9) \\
278(88 \cdot 5)\end{array}$ \\
\hline
\end{tabular}


problem within the clinic. The extent to which these findings can be extrapolated to other clinics in the United Kingdom is uncertain, but all clinics will include some recurrent cases in their annual returns.

It is difficult to establish precise reasons for the increase in the proportion of patients with recurrent herpes between the two years studied. The extensive media coverage that genital herpes has received in recent years may have encouraged more patients with recurrent herpes to attend the clinic to allay fears of an association with cervical cancer and neonatal infection. The introduction of acyclovir and the increasing interest in herpes vaccines could also have encouraged patients with recurrent herpes to attend in the expectation of a cure.

It is likely that improvements have occurred, both in the method of taking swabs from lesions and in the laboratory techniques used to grow the virus, ${ }^{10}$ which have contributed to the increase in the proportion of cultures that were positive in 1982 compared with 1972. The fact that these improvements were sufficient to lead to a significant increase in patients with primary disease but not in those with recurrent herpes, may be partly due to the difference in duration of infection between these two groups. Patients with recurrent attacks shed virus for a much shorter time than those with primary attacks, ${ }^{11}$ and there is thus less chance of a culture being taken while they are shedding virus and consequently of having a positive culture result.

It would be possible to overcome the problems that this study has highlighted by modifying the national recording system so that each case of herpes can be classified as primary, recurrent, or recurrent but not previously recorded. This last category would be necessary as there will be a certain number of patients with recurrent herpes who will have not visited a clinic for their primary or recurrent attacks, and consequently will not have been recorded as a patient with a new attack. Such modifications would provide a better picture of the size of the problem of genital herpes in the population.

\section{References}

1. Communicable Diseases Surveillance Centre, Communicable Diseases (Scotland) Unit and Academic Department of Genitourinary Medicine, Middlesex Hospital Medical School. Sexually Transmitted Disease Surveillance United Kingdom 1982. Communicable Disease Report 1984;84/10.

2. Corey L, Nahmias AJ, Guinan ME, Benedetti JK, Critchlow CW, Holmes KK. A trial of topical acyclovir in genital herpes simplex virus infection. $N$ Engl $J$ Med 1982; 306:1313-9.

3. Mindel A, Adler MW, Sutherland S, Fiddian AP. Intravenous acyclovir treatment for primary genital herpes. Lancet 1982;i:697-700.

4. Nilsen AE, Aasen T, Halsos AM, et al. Efficacy of oral acyclovir in the treatment of initial and recurrent genital herpes. Lancet 1982; i: 571-3.

5. Malone C. The facts behind the love bug scare. Daily Star 1982 August 23:8.

6. Englebardt $\mathrm{S}$. Herpes the sinister virus. Reader's Digest 1982 May: $117-20$.

7. Leo J. The new scarlet letter. Time 1982 August 2:46-50

8. Laskin D. The sex epidemic. Cosmopolitan 1982 July:122-4.

9. Adler MW, Mindel A. Genital herpes: hype or hope? Br Med J 1983;286: 1767-8.

10. Corey L, Holmes KK. Genital herpes simplex virus infections: current concepts in diagnosis, therapy and prevention. Ann Intern Med 1983;98:973-83.

11. Corey L, Holmes KK, Benedetti J, Critchlow C. Clinical course of genital herpes: implications for therapeutic trials. In: Nahmias AJ, Dowdle WR, Schinazi R, eds. The human herpes viruses. New York: Elsevier, 1980. 